\title{
Intermediate to late term results of Mustard's procedure for complete transposition of the great arteries with an intact ventricular septum
}

\author{
FRANCESCA J DARVELL, * I R ROSSI, * MARINEZ B ROSSI, * PFAYERS,

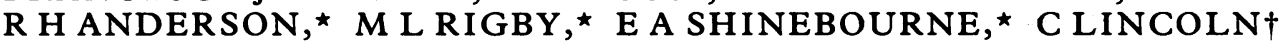 \\ From the Departments of $\star$ Paediatrics and $\dagger$ Surgery, Brompton Hospital, Cardiothoracic Institute, London
}

SUMMARY Overall survival after Mustard's operation was assessed in 130 patients with complete transposition of the great arteries and an intact ventricular septum who were operated on at the Brompton Hospital in the 12 year period from January 1974 to December 1985 . Actuarial analysis $\subseteq$ showed a survival at five years of $79.1 \%$ (25 deaths in 130 patients). Half the deaths occurred within a month of operation and half up to five years later. Operation under the age of three months carried a greater mortality (six deaths in 11 patients). Statistical analysis showed that these survival figures were consistent throughout the series and did not alter with the year of operation.

In the light of recent trends in treatment of this lesion, it is concluded that for neonates an arterial switch procedure is now likely to carry the best chance of long term success. For the patient who presents after the age of three months, however, there may still be a place for the Mustard procedure.

Debate continues about the optimal surgical treatment for complete transposition of the great arteries with an intact ventricular septum. In many centres atrial redirection procedures (Senning or Mustard operation) have an acceptably low mortality. ${ }^{1-3}$ The complications of these operations can be minimised by careful attention to operative detail. ${ }^{45}$ In contrast, the operative mortality of the more recently introduced arterial switch procedure (which produces a more anatomically correct repair) was higher in the early reported series. It has now, however, been demonstrated that the overall results of the arterial approach can match or even surpass those of atrial redirection. ${ }^{6}$

When assessing the merits of these two procedures we must consider both their short term and long term outcome. Such analysis is possible for the atrial redirection procedure, but long term analysis is not as yet possible for the arterial switch procedure. To provide information on atrial redirection we have

Requests for reprints to Professor R H Anderson, Department of Paediatrics, Cardiothoracic Institute, Fulham Road, London SW3 6HP.

Accepted for publication 13 October 1987 studied the immediate to late results of the Mustard operation by examining the records of 130 patients with complete transposition of the great arteries and an intact ventricular septum who were operated on by one surgeon at the Brompton Hospital over a 12 year period.

\section{Patients and methods}

Between January 1974 and December 1985, 136 patients born in Great Britain and attending the Brompton Hospital had a Mustard operation for complete transposition of the great arteries (concordant atrioventricular and discordant ventriculoarterial connections) with intact (or virtually intact) ventricular septation (any ventricular septal defect present was considered to be too small to warrant closure). All the patients with this abnormality who were referred to our hospital during this period were routinely followed up as outpatients at the Brompton Hospital, at Our Lady Hospital for Sick Children, Dublin, or at their referring hospital. Letters indicating the progress and health of the patient were sent to the consultants at the Brompton Hospital if the child was not followed up there. The notes of 130 of these patients were examined retrospectively. Six sets of 
notes could not be traced because of loss. Follow up in the studied patients was complete.

We recorded the age and sex of the patient, the year of operation, the source of referral (United Kingdom or Ireland), the cardiopulmonary bypass technique, whether or not profound hypothermia was used with circulatory arrest, the type of atrial baffle, the presence of either preoperative or postoperative rhythm problems or both, the presence of associated abnormalities, and the need for reoperation.

The quality of life was not assessed because this was considered inappropriate in a retrospective study. We are currently assessing this aspect by prospective objective (including formal exercise testing) and subjective tests.

Ninety patients were referred from hospitals in the United Kingdom and $\mathbf{4 0}$ from centres in Ireland. The age range was 3 days to 9 years 8 months with a mean age of 1 year 5 months. There were 97 boys and 33 girls. Circulatory arrest was used in $\mathbf{4 8}$ children during their operation while 82 had cardiopulmonary bypass. The baffle was made of dura mater in 24 cases, of Dacron in 68 cases, of bovine pericardium in 23 , and of Teflon in one. In 14 cases, the type of baffle material used was not recorded in the notes.

Twenty four children had persistent patency of the arterial duct, 17 had left ventricular outflow trace obstruction of various types, nine had haemodynamically insignificant defects of the ventricular septum (which were not closed at surgery), two had aortic coarctation, and one patient had stenosis of the pulmonary valve.

The data were analysed and survival curves were plotted by actuarial methods. ${ }^{7}$ The survival curves were compared and prognostic factors were examined by the log rank test ${ }^{8}$ and Cox $^{9}$ models.

\section{Results}

Table 1 shows the age of operation and cumulative mortality for the 130 patients on whom follow up data were available. Twenty five (19\%) of the 130 patients died. The death rate was significantly higher in

Table 1 Mortality related to age at operation *

\begin{tabular}{|c|c|c|c|c|}
\hline \multirow{2}{*}{$\begin{array}{l}\text { Age at } \\
\text { operation }\end{array}$} & \multirow{2}{*}{$\begin{array}{l}\text { No of } \\
\text { patients }\end{array}$} & \multicolumn{2}{|l|}{ Deaths } & \multirow{2}{*}{$\begin{array}{l}\text { Overall } \\
(\%)\end{array}$} \\
\hline & & Early & Late & \\
\hline $\begin{array}{l}0-3 \text { months } \\
3 \text { months }-1 \text { year } \\
1-2 \text { years } \\
2-5 \text { years } \\
5-10 \text { years } \\
\text { Total }\end{array}$ & $\begin{array}{r}11 \\
43 \\
51 \\
22 \\
3 \\
130\end{array}$ & $\begin{array}{r}5 \\
1 \\
6 \\
1 \\
0 \\
13\end{array}$ & $\begin{array}{r}1 \\
6 \\
3 \\
2 \\
0 \\
12\end{array}$ & $\begin{array}{r}55 \\
16 \\
18 \\
14 \\
0 \\
19\end{array}$ \\
\hline
\end{tabular}

*Later in the series younger patients will have shorter periods of follow up.

"Early" death refers to those within 30 days of operation. children aged less than three months at the time of operation (fig 1 and 2). Analysis of the other variables and possible risk factors listed in the methods section showed that no other feature was significantly associated with length of survival. Trends were demonstrated with some variables but for the numbers of patients analysed none of the observed trends was statistically significant.

Six of the 24 children with a patent arterial duct died. Three of the 17 children with obstruction of the left ventricular outflow tract also died, although the gradients in these three were not significantly greater than the values for this overall subset. All those with an associated but haemodynamically insignificant ventricular septal defect, coarctation, or pulmonary valve stenosis survived operation. Thirteen patients had a second operation because of obstruction of the superior caval vein in five, pulmonary venous obstruction in four, inferior caval venous obstruction in three, and dehiscence of the patch around the suture line in the other. Four of these children died; three had been operated on because of presumed pulmonary venous obstruction. Two of these children were shown not to have pulmonary venous obstruction. In both the high pulmonary arterial pressure measured preoperatively reflected pulmonary vascular disease rather than obstruction. The distinction between the two conditions at catheterisation rests on the pulmonary arterial wedge pressure. This should be low in the setting of pulmonary vascular disease whereas, with venous obstruction, the pressure is high. Unfortunately, it is difficult to obtain true wedge (that is, pulmonary venous atrial) pressures in patients with pulmonary vascular disease. Because of this, a recorded high wedge pressure may not distinguish between pulmonary vascular disease and obstruction. The fourth death occurred in the perioperative period in a child who had thrombosis of the superior vena cava (see table 2 ).

Table 3 shows the time after the first operation until death. Half the group died within a month of operation and half more than one month after operation-deaths occurred up to five years after

Table 2 Reasons for reoperation and results of reoperation

\begin{tabular}{lccc}
\hline $\begin{array}{l}\text { Indication for } \\
\text { reoperation }\end{array}$ & $\begin{array}{l}\text { No of } \\
\text { patients }\end{array}$ & Deaths & Cause of death \\
\hline $\begin{array}{l}\text { SCV obstruction } \\
\begin{array}{l}\text { Pulmonary venous } \\
\text { obstruction }\end{array}\end{array}$ & 5 & 1 & $\begin{array}{c}\text { Thrombosis in } \\
\text { SCV } \\
\text { Pulmonary } \\
\text { vascular } \\
\text { disease in two }\end{array}$ \\
$\begin{array}{l}\text { ICV obstruction } \\
\text { Patch dehiscence }\end{array}$ & 3 & 3 & - \\
$\begin{array}{l}\text { Total } \\
\text { SCV }\end{array}$ & 13 & - & \\
\hline
\end{tabular}

SCV, superior caval vein (vena cava); ICV, inferior caval vein (vena cava). 


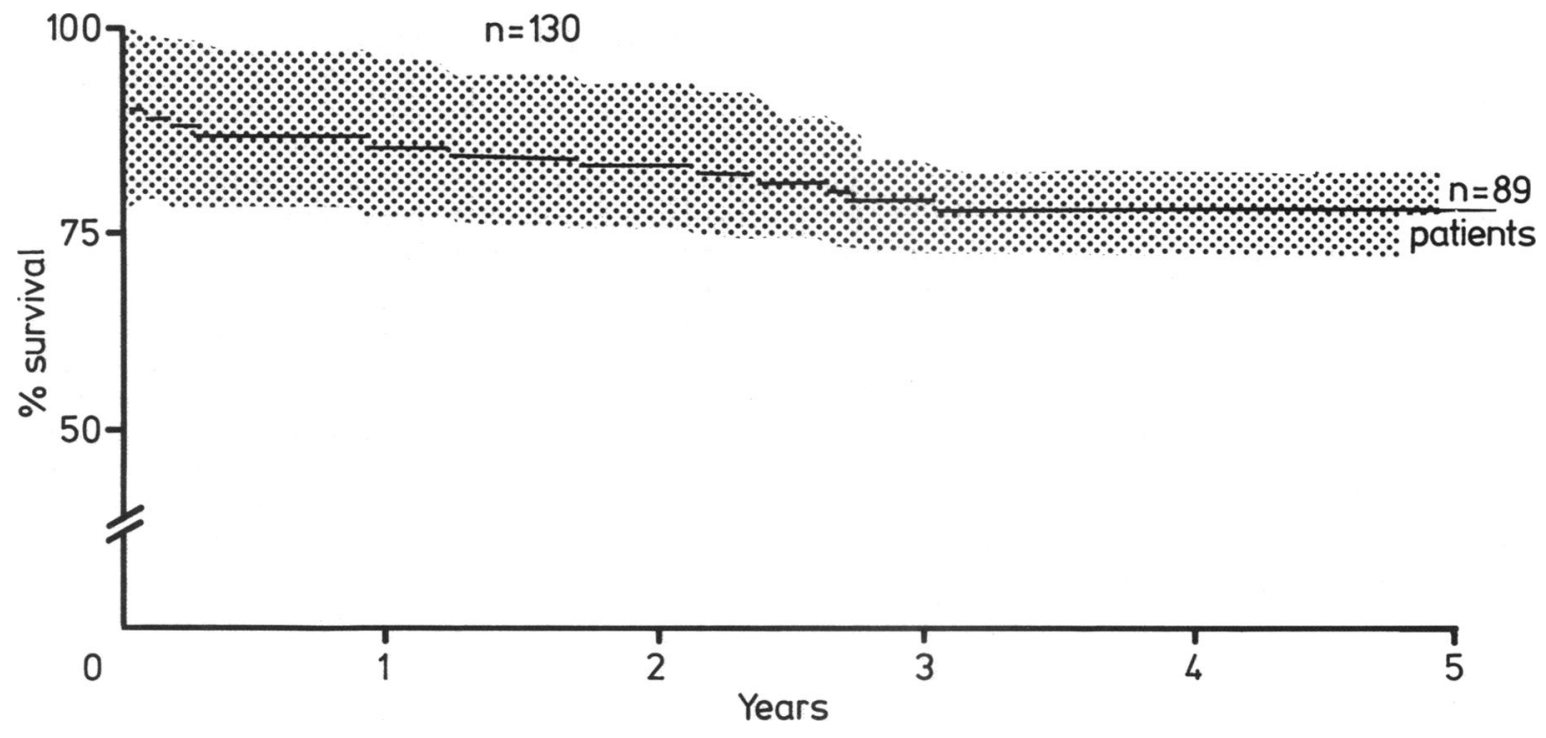

Fig 1 Actuarial survival curve for the overall population. The stippled area shows the $70 \%$ confidence interval.

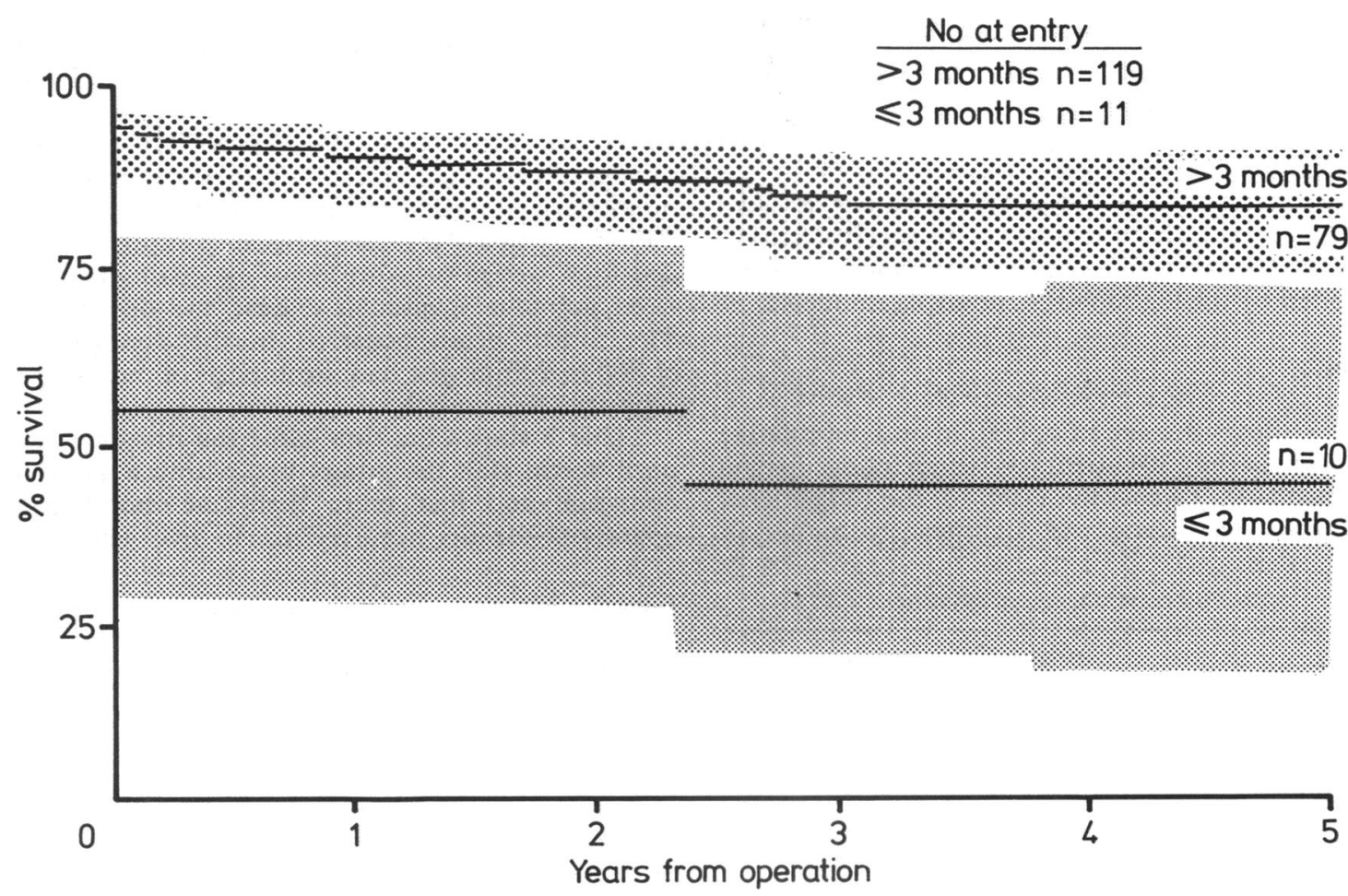

Fig 2 Actuarial survival curves for the groups of patients aged over three months ( $n=119)$ or less than three months $(n=11)$ at repair. The shaded areas show the $70 \%$ confidence intervals. 
Table 3 Time until death after first operation

\begin{tabular}{|c|c|c|c|c|c|c|}
\hline Age at operation & $48 h$ & 2 days -1 mnth & 1 mnth-1 yr & $1-2 y r$ & $>2 y r$ & Total \\
\hline $\begin{array}{l}3 \text { mnth } \\
3 \text { mnth-12 mnth } \\
12 \text { mnth-24 mnth } \\
2-5 \mathrm{yr} \\
\text { Total }\end{array}$ & $\begin{array}{l}4 \\
1 \\
2 \\
1 \\
8\end{array}$ & $\begin{array}{l}1 \\
\overline{4} \\
\overline{5}\end{array}$ & $\begin{array}{l}- \\
2 \\
1 \\
1 \\
4\end{array}$ & $\begin{array}{l}\overline{2} \\
- \\
\overline{2}\end{array}$ & $\begin{array}{l}1^{\star} \\
2 \\
2 \\
1 \\
6\end{array}$ & $\begin{array}{r}6 \\
7 \\
9 \\
3 \\
25\end{array}$ \\
\hline
\end{tabular}

*Death caused by pulmonary vascular disease (one child in each case).

operation. Table 4 shows the causes of death (where they could be determined). Of the 11 children dying with low cardiac output, seven were known to have had postoperative arrhythmias. Four children had nodal rhythm (one of these was also in renal failure), two had periods of supraventricular tachycardia, and one was known to have atrial fibrillation. The other four children were in sinus rhythm. As stated previously all three children with pulmonary vascular disease died within two and a half years of operation; in one patient who died the Mustard procedure had been carried out as early as 11 weeks of age.

Necropsies on two children showed pulmonary venous obstruction (one five months and the other three years after operation). Neither of these children had had a second operation and, hence, are not included in table 3. Another child died of cerebral damage within two months of operation. Two children died suddenly. Death occurred 10 months after operation in the first and necropsy showed venous obstruction of the inferior vena cava. The other child had been treated for arrhythmias that developed nearly three years after operation. Electrocardiograms showed atrial flutter with 3:1 atrioventricular conduction. Direct current cardioversion and antiarrhythmic agents were used to control the

Table 4 Cause of death

\begin{tabular}{|c|c|c|}
\hline Known cause of death & No & Time after operation \\
\hline $\begin{array}{l}\text { Low cardiac output/ } \\
\text { cardiac arrest }\end{array}$ & 11 & 10 within 7 days, 1 at 1 mnth \\
\hline Pulmonary vascular disease & 3 & $18-30$ mnth \\
\hline Respiratory infections & 3 & $2-5$ yr \\
\hline $\begin{array}{l}\text { Pulmonary venous } \\
\text { obstruction }\end{array}$ & 2 & 5 mnth and 3 yr \\
\hline $\begin{array}{l}\text { Cerebral damage after } \\
\text { operation }\end{array}$ & 1 & 2 mnth \\
\hline $\begin{array}{l}\text { Thrombosis in superior } \\
\text { caval vein (vena cava) }\end{array}$ & 1 & 1 week \\
\hline $\begin{array}{l}\text { Sudden death, obstruction } \\
\text { of inferior caval vein } \\
\text { (vena cava) }\end{array}$ & 1 & 10 mnth \\
\hline Sudden death, arrhythmias & 1 & 2 yr 8 mnth \\
\hline Gastroenteritis & 1 & 3 mnth \\
\hline $\begin{array}{l}\text { In postoperative period } \\
\text { after an oesophageal } \\
\text { operation }\end{array}$ & 1 & \\
\hline Total & 25 & \\
\hline
\end{tabular}

arrhythmias but the child died suddenly two months after their onset.

Five children died after operation from causes not directly attributable to their cardiovascular state. Three died of respiratory infections between two and five years after operation. No other cause of death was known. One child died of gastroenteritis three months after operation and another died in the perioperative period after an oesophageal operation two years after the Mustard operation.

\section{Discussion}

There are protagonists for both the atrial ${ }^{12}$ and the arterial $^{610}$ approaches for management of children with complete transposition of the great arteries with an intact ventricular septum. The best results published for each operation lend strong support to both viewpoints. As always, hospital rather than population based series raise the question of case selection. Do the surgical results of the given hospital forecast that were all the patients in the population with a particular anomaly to be operated on at that hospital similar results would be obtained? The surgical results in any centre will be improved if the sickest patients do not survive to reach hospital. For this reason, results for patients treated in one hospital may not be directly comparable with those in another. With these caveats in mind, each unit must try to determine the optimal treatment for complete transposition and intact ventricular septum on the basis of its own results, while taking note of results at other centres. In this study we have attempted to look critically at our own results for interatrial repair of complete transposition.

The overall five year actuarial survival was $79 \%$ (70\% confidence interval $68 \%$ to $87 \%$ ). Further analysis indicated that those who were less than three months old when they were operated on had a significantly worse five year actuarial survival (45\% ( $70 \%$ confidence interval $21 \%$ to $72 \%$ )) than those operated on when they were older $(82 \% \quad(70 \%$ confidence interval $70 \%$ to $90 \%$ )). In all those who were less than three months at operation, operation was not undertaken electively. The indications were either failure to thrive or else persistently severe 
cyanosis with or without metabolic acidosis. It may well be that had atrial redirection been performed electively at an earlier age these results could have been improved. Against this must be set the results of other series ${ }^{311}$ which have shown young age to be a risk factor for atrial redirection, albeit with the age cut off at one month rather than three months as in our series.

Can we now use this data to plan a protocol for the future management of patients referred to our centre with complete transposition and intact ventricular septum? For neonates it is difficult on the basis of our experience to counter the excellent results obtained in selected centres for the arterial switch procedures. ${ }^{6}$ Bearing in mind the caveats discussed above, and also the lack of long term follow up for the arterial procedure (which cannot be overemphasised), it still seems that the arterial switch procedure will offer a better chance of long term survival for the neonate than the Mustard operation. This view is reinforced by finding that in our own centre $23(18 \%)$ patients who had balloon atrial septostomy died before correction of the defect could be attempted. ${ }^{12}$

Nevertheless, our experience is limited to the Mustard variant of complete transposition. It could well be argued that the Senning operation, which is said to overcome the problems of venous obstruction and, possibly, rhythm disturbances, could improve the long term outcome of the redirection procedure. So far follow up after the Senning operation is also limited and as yet we see no compelling evidence to persuade us to change from one to the other atrial redirection procedure. We believe that for the neonate with complete transposition and intact ventricular septum the arterial switch procedure carries the better chance of success in our centre. Our own initial results with this approach ${ }^{13}$ bear out this viewpoint, as do those from some other centres. ${ }^{614}$

But what of the patient referred after the neonatal period? Such patients continue to reach our wards. Here the solution is not nearly so clear cut. Preparative surgery would be required in such patients to make the arterial procedure a realistic alternative. The risks of these palliative procedures have not been analysed in the same depth as those for the arterial switch performed during the neonatal period. In this latter group, therefore, particularly those above the age of three months, we recommend the Mustard procedure. More rigorous analysis of the two stage arterial switch procedures may lead us to revise our opinion.

It was noteworthy that one child in our study developed pulmonary vascular disease and died despite having an operation at 11 weeks of age. It is known that high pulmonary vascular resistance (above 8 units $/ \mathrm{m}^{2}$ ) greatly increases the risk of
Mustard's operation with intact ventricular septum. We have not, however, found other published reports of pulmonary vascular diseases progressing in children with simple complete transposition who had the Mustard operation before they were three months old. ${ }^{15}$ The occurrence of such changes in even one patient in our series strongly supports the trend for earlier correction promoted by the use of the arterial switch procedure during the neonatal period.

We thank Professor Connor Ward of Dublin, who referred many patients for operation and made available their follow up data, and Dr Janet Darbyshire of the Medical Research Council external staff who gave valuable advice during the design of the study.

R H A is supported by the Joseph Levy Foundation and the British Heart Foundation. I R R and M B R were visiting fellows from the Institute of Cardiology, Porto Alegre, Rio Grande do Sul, Brazil. $P F$ is a member of the external staff of the Medical Research Council.

\section{References}

1 Stark J. Transposition of the great arteries. Which operation? Ann Thorac Surg 1984;38:429-31.

2 Oerlert H, Schaps D, Lukmer I, Kallfelz HC, Borst HG. Five years experience with the Mustard operation, 1974-1979. In: Becker AE, Losekoot G, Marcelletti C, Anderson RH, eds. Paediatric cardiology, Vol 3. Churchill Livingstone, Edinburgh: 1981: 200-10.

3 DeLeon VH, Hougen TJ, Norwood I, Lang P, Marx GR, Casteneda A. Results of Senning operation for transposition of the great arteries with intact ventricular septum in neonates. Circulation 1984;70(suppl I):1-21.

4 Turley K, Ebert PA. Total correction of transposition of the great arteries. Conduction disturbances in infants younger than three months of age. $J$ Thorac Cardiovasc Surg 1978;76:312-20.

5 Ullal RR, Anderson RH, Lincoln C. Mustard's operation modified to avoid dysrhythmias and pulmonary and systemic venous obstruction. $J$ Thorac Cardiovasc Surg 1979;78:431-9.

6 Quaegebeur JM, Rohmer J, Ottenkamp J, et al. The arterial switch operation. An eight year experience. $J$ Thorac Cardiovasc Surg 1986;92:361-84.

7 Peto R, Pike MC, Armitage P, et al. Design and analysis of randomised clinical trials requiring prolonged observation of each patient. I. Introduction and design. Br J Cancer 1976;34:585-612.

8 Peto R, Pike MC, Armitage P, et al. Design and analysis of randomised clinical trials requiring prolonged observation of each patient. II. Analysis and examples. $\mathrm{Br} J$ Cancer 1977;35:1-39.

9 Cox DR. Regression models and life tables. $J$ Roy 
Statist Soc B 1972;34:187-220.

10 Sidi D, Planche C, Kachener J, et al. Anatomic correction of simple transposition of the great arteries in $\mathbf{5 0}$ neonates. Circulation 1987;75:429-35.

11 Gutgesell HP, Garson A, McNamara DG. Prognosis for the newborn with transposition of the great arteries. Am J Cardiol 1979;44:96-9.

12 Mok Q, Darvell FJ, Mattos S, et al. Survival after balloon atrial septostomy in complete transposition of the great arteries. Arch Dis Child 1987;62:549-53.
13 Kanter KR, Anderson RH, Lincoln C, Rigby ML, Shinebourne EA. Anatomic correction for complete transposition and double outlet right ventricle. $J$ Thorac Cardiovasc Surg 1985;90:690-9.

14 Kirklin JW, Barratt-Boyes BG. Cardiac surgery. New York: John Wiley \& Sons, 1985: 1197-8.

15 Mahoney L, Turley K, Ebert P, Heymann MA. Longterm results after atrial repair of transposition of the great arteries in early infancy. Circulation 1982;66:253-8. 